\title{
Article \\ Variations of Serum Oxidative Stress Biomarkers under First-Line Antituberculosis Treatment: A Pilot Study
}

\author{
Andreea-Daniela Meca ${ }^{1}\left(\mathbb{D}\right.$, Adina Turcu-Stiolica ${ }^{2, *}$ (D) Elena Camelia Stanciulescu ${ }^{3}$, Ana Marina Andrei ${ }^{3}$, \\ Floarea Mimi Nitu ${ }^{4}$, Ileana Monica Banita ${ }^{5}$, Marius Matei ${ }^{5}$ and Catalina-Gabriela Pisoschi ${ }^{3}$ \\ 1 Department of Pharmacology, University of Medicine and Pharmacy of Craiova, 200349 Craiova, Romania; \\ andreea_mdc@yahoo.com \\ 2 Department of Pharmacoeconomics, University of Medicine and Pharmacy of Craiova, \\ 200349 Craiova, Romania \\ 3 Department of Biochemistry, University of Medicine and Pharmacy of Craiova, 200349 Craiova, Romania; \\ camiparsot@yahoo.com (E.C.S.); marinafusaru@yahoo.com (A.M.A.); c_pisoschi@yahoo.com (C.-G.P.) \\ 4 Department of Pneumology, University of Medicine and Pharmacy of Craiova, 200349 Craiova, Romania; \\ dr_nitumimi@yahoo.com \\ 5 Department of Histology, University of Medicine and Pharmacy of Craiova, 200349 Craiova, Romania; \\ monica.banita@yahoo.com (I.M.B.); mariusmatei44@yahoo.com (M.M.) \\ * Correspondence: adina.turcu@gmail.com; Tel.: +40-726-270-295
}

Citation: Meca, A.-D.; Turcu-Stiolica, A.; Stanciulescu, E.C.; Andrei, A.M.; Nitu, F.M.; Banita, I.M.; Matei, M.; Pisoschi, C.-G. Variations of Serum Oxidative Stress Biomarkers under First-Line Antituberculosis Treatment: A Pilot Study. J. Pers. Med. 2021, 11, 112. https://doi.org/10.3390/ jpm11020112

Academic Editor: Kentaro Inamura Received: 31 December 2020 Accepted: 5 February 2021

Published: 9 February 2021

Publisher's Note: MDPI stays neutral with regard to jurisdictional claims in published maps and institutional affiliations.

Copyright: (c) 2021 by the authors. Licensee MDPI, Basel, Switzerland. This article is an open access article distributed under the terms and conditions of the Creative Commons Attribution (CC BY) license (https:/ / creativecommons.org/licenses/by/ $4.0 /)$.

\begin{abstract}
Tuberculosis (TB) is one of the highest infectious burdens worldwide, and pathogenesis is yet incompletely elucidated. Bacilli dissemination is due to poor antioxidant defense mechanisms and intensified oxidative stress. There are few recent studies that analyzed and compared free radicals or antioxidant status before and after anti-TB treatment. Hence, the present study underlines the need to identify oxidative stress as it could be a useful tool in TB monitorisation. Thirty newly diagnosed patients with pulmonary TB were included after signing an informed consent. Blood was collected before receiving first-line anti-tubercular therapy (T0) and after 60 days (T2). Spectrophotometric methods were used to quantify oxidative parameters (TBARS—-thiobarbituric acid reactive species); enzymatic antioxidants such as SOD (superoxide dismutase), CAT (catalase), GPx (glutathione peroxidase), and TAC (total antioxidant capacity); and non-enzymatic antioxidants such as GSH (reduced glutathione). A moderate positive correlation was found between GSH and TAC $(r=0.63$, $p$-value $=0.046)$ and GSH and SOD $(r=0.64, p$-value $=0.041)$ at T2. Increased values of GSH, CAT, and SOD were noted at T2 in comparison with T0, while GPx, TAC, and TBARS decreased at T2. A better monitorisation in TB could be based on oxidative stress and antioxidant status. Nevertheless, restoring redox host balance could reduce $\mathrm{TB}$ progression.
\end{abstract}

Keywords: oxidative stress; tuberculosis; glutathione; superoxide-dismutase; catalase; antioxidant

\section{Introduction}

The World Health Organisation (WHO) announced in 2019 that, in Europe, 30 people are diagnosed with active tuberculosis (TB) every hour [1]. Although TB is still one of the highest burdens worldwide, pathogenic mechanisms are yet incompletely known [2-5]. Identification of oxidative stress involvement in TB could lead to better disease monitorisation [6].

Mycobacterium tuberculosis (M.tb), the aetiological agent of TB, is capable of high and long-term persistence within macrophages by inhibiting phago-lysosomal fusion [3-5]. Latent infection appears as a response of $M . t b$. maintenance in a low replicative state (latent TB), with support of T- and B-lymphocytes [3-5]. If alveolar macrophages further attract more immune cells such as monocytes and neutrophils, an inflammatory granuloma will be formed, as M.tb. subverts host immunity and survives [7,8]. Although, within the granuloma, immune cells interact and trigger immune responses in order to control $\mathrm{TB}$, macrophages can undergo respiratory burst, generating oxidative stress and initiating active pulmonary TB $[4,7,8]$. Bacilli release and infection progression are consequences of 
lipid peroxidation, parenchymal tissue destruction, and insufficient antioxidant defence mechanisms $[3,9,10]$. The higher the bacterial load, the more advanced will be the necrosis; therefore, an immunological fight between M.tb. and the individual will establish disease consequences $[3,9,11,12]$.

Nevertheless, host damage is generated owing to the imbalance between reactive oxygen species (ROS) and antioxidants [10,12]. ROS reduce defence autophagic and apoptotic host mechanisms, but can also inhibit the pathogen development along the lung, by destroying mycobacterial DNA, activating lipid peroxidation, and destabilizing proteins $[5,7,10,12,13]$. Moderate ROS concentrations ensure functionality of signalling pathways and immunoregulation, but an excess affects cellular homeostasis in an uncontrolled manner $[14,15]$. Lipid peroxidation leads to M.tb. membrane disruption by affecting the double chemical bonds of polyunsaturated lipids [5]. Even more highly toxic and powerful free radicals, such as superoxide $\left(\mathrm{O}_{2}^{-}\right)$and hydroxyl $\left(\mathrm{OH}^{-}\right)$, are generated after mitochondrial oxidative burst [16]. However, M.tb. antioxidant system could cross over ROS activity and lead to long-term bacilli survival and inflammatory response [5].

On the other hand, the incremental autophagic capacity of macrophages can be supported through host antioxidant activity [5]. Both enzymatic (superoxide dismutase (SOD), catalase (CAT), and glutathione peroxidase (GPx)) and non-enzymatic antioxidants (reduced glutathione (GSH)) remove ROS before DNA, proteins, or lipids attack and ensure direct anti-inflammatory effects and adaptative immunological response $[5,15]$. Superoxide radicals can be converted through $\mathrm{SOD}$ intervention to $\mathrm{H}_{2} \mathrm{O}_{2}$, as an adaptive response [6,15]. CAT counteracts $\mathrm{H}_{2} \mathrm{O}_{2}$ higher concentrations, while GPx catalyses reduction of both organic peroxides and $\mathrm{H}_{2} \mathrm{O}_{2}$ [14,15]. GPx, glutathione oxidase, and glutathione reductase provide cellular detoxification and lower ROS damage through the glutathione redox cycle, using the sulfhydryl group of cysteine as a proton donor [15]. Therefore, antioxidants prevent severe TB manifestations and counteract tissue degradation $[5,15]$.

The amount of ROS generated to kill M.tb. can be spectrophotometrically measured by following plasmatic levels of malondialdehyde (MDA) and other thiobarbituric acid reactive species (TBARS) (conclusive for lipid peroxidation) or protein carbonyls thiols (conclusive for protein oxidation) $[8,12,17]$. Enzymatic antioxidants can also be traced and quantified in order to measure the host capacity to prevent any oxidative damage $[8,12,17]$.

Our pilot study compared blood levels of oxidative and antioxidant biomarkers in pulmonary TB patients, before and after 60 days of first-line antituberculosis treatment, and further correlated the values, as awareness of oxidative stress in pulmonary TB could lead to better understanding of TB pathogenesis and possible monitorisation of this highly infectious disease.

\section{Materials and Methods}

\subsection{Study Design}

The prospective study received approval from the Ethics Committee from The University of Medicine and Pharmacy of Craiova, Romania (Nr.5/17.01.2019). We included thirty newly diagnosed pulmonary active TB adults, of both genders, aged between 18 and 65 years, who had not received more than one week of first-line anti-TB treatment. Patients hospitalized at "Victor Babeș" Clinical Hospital of Infectious Diseases and Pneumophthisiology Craiova and Pneumology Hospital Leamna, Dolj County, from Romania, were recruited after obtaining their written informed consent. All the patients were diagnosed with active TB after sputum-smear positivity test and further confirmed through radiologic and clinical examinations. Patients diagnosed with other different chronic illness, pregnant women, and children met exclusion criteria of our study. After examination of patient disease history, individuals with extra-pulmonary TB, HIV infection, cancer, hypertension, hepatic or renal insufficiency, diabetes, and parathyroid gland dysfunctionalities were excluded. Patients who were administered antioxidants, vitamin D supplements, or medication that may interfere with vitamin D plasmatic levels (theophylline, some anti- 
convulsants, thiazide diuretics, corticosteroids) were also excluded, as vitamin D presents immunomodulatory roles and influences oxidative biomarkers [18-20].

Venous blood samples were collected before receiving treatment (T0) and after 60 days (T2) of initial intensive phase of first-line regimen (isoniazid, rifampicin, ethambutol, pyrazinamide). TB regimen was given in accordance with the Revised National Tuberculosis Control Program and DOTS strategy (direct observed short course chemotherapy), adjusting doses by patients' weight. We used heparinized, $\mathrm{K}_{2}$ EDTA, and without any anticoagulant BD vacutainers (Becton Dickinson, USA), according to the manufacturer's recommendations, to collect blood from each patient who approved participation. Part of blood samples was further processed and centrifuged at $1000 \times g$ (Eppendorf centrifuge 5417R, Eppendorf AG, Hamburg, Germany), within 30 min after collection, and then serum/plasma, whole blood, and hemolysate were aliquoted (minimum of $500 \mu \mathrm{L}$ ). All samples were stored at $-80^{\circ} \mathrm{C}$ until laboratory assessments of biomarkers.

\subsection{Biochemical Analysis}

Oxidative stress biomarkers were quantified using spectrophotometric methods in vitro, by manual use [21-26]. TBARS were measured in order to quantify lipid peroxidation. Enzymatic activities of SOD, CAT, GPx, and TAC (total antioxidant capacity) were assessed using hemolysates or whole blood for standard procedures. GSH was the only non-enzymatic antioxidant quantified in the present study.

\subsubsection{Determination of SOD Activity}

For measurement of SOD activity, the blood was processed for haemolysis. Centrifugation at $1100 \times g$, for $10 \mathrm{~min}$, was performed for $0.5 \mathrm{~mL}$ of blood and the upper plasma was removed. Erythrocytes pellet was washed four times with physiologic saline solution, centrifuging $10 \mathrm{~min}$ after each wash, and after the final wash, erythrocytes were diluted at $2 \mathrm{~mL}$ with cold redistilled water, mixed, and kept at $+4{ }^{\circ} \mathrm{C}$ for $10 \mathrm{~min}$. A 100 -fold dilution of the lysate with $0.01 \mathrm{M}$ phosphate buffer saline (PBS) $\mathrm{pH}=7$ is necessary before performing SOD assay using a Ransod kit (Randox Laboratories, Crumlin, County Antrim, UK). SOD activity was quantified from the degree of inhibition of the reaction between superoxide radicals, generated after the oxidation of xanthine $(0.05 \mathrm{mmol} / \mathrm{L})$ with xanthine oxidase (80 UI/L), and 2-(4-iodophenyl)-3-(4-nitrophenol)-5-phenyltetrazolium chloride (INT, 0.025 $\mathrm{mmol} / \mathrm{L}$ ). A DU65 UV/VIS spectrophotometer (Beckman, Germany) was used to measure the absorbance of the pink formazan at $505 \mathrm{~nm}$. A unit of SOD activity represents the quantity of SOD that determines a 50\% inhibition of INT reduction rate. In order to determine the percentage of inhibition for each sample, diluted samples and standards rates were converted into percentages of a sample diluent rate after subtraction from $100 \%$, and assigned a value for the rate of the uninhibited reaction. SOD activity was expressed as SOD units/ $\mathrm{mL}$ of whole blood.

\subsubsection{Determination of GPx Activity}

GPx activity was measured using the Ransel kit (Randox Laboratories, Crumlin, County Antrim, UK) based on a UV method proposed by Paglia and Valentine [27]. GPx from the sample of heparinized whole blood catalyses the oxidation of GSH $(4 \mathrm{mmol} / \mathrm{L})$ by cumene hydroperoxide $(0.18 \mathrm{mmol} / \mathrm{L})$. Oxidised glutathione (GSSG) is converted to GSH in the reaction catalysed by glutathione reductase $(>0.5 \mathrm{U} / \mathrm{L})$ in the presence of NADPH (reduced form of nicotinamide adenine dinucleotide phosphate) $(0.34 \mathrm{mmol} / \mathrm{L})$, leading to a decrease in absorbance, which was further measured at $340 \mathrm{~nm}$. The optical density was measured using the UV/VIS spectrophotometer Beckman. Heparinized whole blood was previously diluted with diluting agent and Drabkins' reagent to inhibit the interference of other blood peroxidases. GPx activity was expressed as U/L of haemolysate.

In order to determine GSH concentration and CAT activity, we blended equal volumes of blood and cold distillate water, and then centrifugated the mixture for $15 \mathrm{~min}$ at $4000 \times g$ 
(Eppendorf refrigerated centrifuge 5417 R, Eppendorf AG, Hamburg, Germany) to obtain a clear haemolysate.

\subsubsection{Determination of CAT Activity}

For CAT activity determination, we used the Aebi method based on direct quantification of hydrogen peroxide decomposition rate by CAT and haemoglobin within the sample [28-30]. All the samples were diluted 1:10, mixed with $0.07 \mathrm{M} \mathrm{PBS}, \mathrm{pH}=7$, following an incubation at $37^{\circ} \mathrm{C}$ for $10 \mathrm{~min}$. The decrease of absorbance at $240 \mathrm{~nm}$ after hydrogen peroxide addition was read using the DU65 UV/VIS Beckman spectrophotometer. CAT activity was assessed through the molar extinction coefficient of hydrogen peroxide, as one unit of CAT is considered to decompose $1 \mu \mathrm{mol}$ of hydrogen peroxide during $1 \mathrm{~min}$. Therefore, CAT activity was expressed as unit per $\mathrm{mg}$ of haemoglobin $(\mathrm{U} / \mathrm{mgHb})$, measured using flow-cytometry on automated analyzers.

\subsubsection{Determination of GSH Concentration}

Samples of each haemolysate were treated with $5 \%$ trichloroacetic acid (TCA, $v / v$ ), blended, and separated after $5 \mathrm{~min}$ of centrifugation at $28,000 \times g$ at a lower temperature $\left(4{ }^{\circ} \mathrm{C}\right)$. Each supernatant was then combined with a solution of 5,5'-dithio-bis-(2nitrobenzoic acid) (DTNB, Ellman's reagent) $(0.01 \mathrm{M})$ in $0.07 \mathrm{M}$ PBS, $\mathrm{pH}=8$ (1:50 ratio, $v / v)$, and incubated for $45 \mathrm{~min}$ in the dark and at room temperature (RT). The absorbance of the pale-yellow product at $412 \mathrm{~nm}$ was measured with a UV/VIS spectrophotometer Kruss (Hamburg, Germany) and then converted to GSH concentration according to the GSH standard curve and expressed as $\mathrm{mg} / \mathrm{dL}$.

\subsubsection{Total Antioxidant Capacity (TAC) Assay}

A spectrophotometrically evaluation of TAC in blood samples is one of the assays usually performed to assess the body's ability to produce antioxidants and combat the oxidative stress [21-26]. Each plasma sample was diluted with $0.01 \mathrm{M}$ PBS, $\mathrm{pH}=7.4$ (1:25 ratio, $v / v)$, combined in equal volumes with $0.1 \mathrm{mM} 2,2^{\prime}$-diphenyl-1-picrylhydrazyl radical reagent (DPPH), and further incubated in the dark and at RT for $30 \mathrm{~min}$. After a 3 min centrifugation at $20,000 \times g$, the absorbance at $520 \mathrm{~nm}$ was read with the UV/VIS spectrophotometer Kruss. All the reagents were provided by Sigma-Aldrich, Germany and TAC was expressed as mmol DPPH/L.

\subsubsection{Thiobarbituric Acid Reactive Substances Assay}

This assay was performed for the evaluation of the lipid peroxidation level by quantifying plasmatic MDA concentration, its major final product [21,22]. Plasma samples were mixed with equal volumes of $5 \% \mathrm{TCA}$ and Tris-HCl $(0.2 \mathrm{M}) \mathrm{pH}=4.7(v / v)$ and incubated $10 \mathrm{~min}$ at RT. Next, $0.55 \mathrm{M}$ thiobarbituric acid (TBA) solution in sodium sulphate (2 M) was added and the mixture was incubated at $90{ }^{\circ} \mathrm{C}$ for $45 \mathrm{~min}[24,25]$. After ice cooling, a 3 min centrifugation $(15,000 \times g)$ was carried out with the same refrigerated centrifuge. During this procedure, a coloured product between MDA and TBA is formed, with its absorbance at $532 \mathrm{~nm}$ being measured with the same UV/VIS spectrophotometer Kruss. The molar extinction coefficient of MDA $\left(1.55 \times 105 \mathrm{M}^{-1} \mathrm{~cm}^{-1}\right)$ supported our calculation of TBARS concentration, expressed as $\mu \mathrm{mol} / \mathrm{L}$. Almost all the reagents were provided from Sigma-Aldrich, Germany, except TBA, obtained from Fluka.

\subsection{Statistical Analysis}

Data were analyzed using the GraphPad Prism 9.0 software (GraphPad Software, San Diego, CA, USA). The results are presented as mean \pm standard deviation (SD) and range. The nonparametric Wilcoxon matched-pairs signed rank test was used to evaluate the significant differences between variables at $\mathrm{T} 0$ and $\mathrm{T} 2$. It was considered statistically significant at the $5 \%$ level (two-tailed). 
The strength of the quantitative relationship between the different clinical characteristics of the patients was measured with Spearman coefficients and heatmap of correlation matrix.

\section{Results}

We included 30 patients, but only 15 were analyzed during the period of study, as for them, it was possible to concomitantly quantify all the parameters at T0 and T2. Their range for age was 32-61 years and for weight was 39-64 kg. Table 1 includes the demographic characteristics of our patients, whereas Table 2 summarizes the clinical characteristics at both points in time.

Table 1. Demographic characteristics of the patients.

\begin{tabular}{lc}
\hline \multicolumn{1}{c}{ Demographic Data } & Values: Mean $( \pm$ SD) or $\boldsymbol{n}(\mathbf{\%})$ \\
\hline Age & $48.80( \pm 9.283)$ \\
Weight & $54.27( \pm 8.189)$ \\
Gender & \\
$\quad$ Female & $4(26.7 \%)$ \\
$\quad$ Male & $11(73.3 \%)$ \\
Environment & \\
$\quad$ Urban & $4(26.7 \%)$ \\
$\quad$ Rural & $11(73.3 \%)$ \\
\hline
\end{tabular}

Table 2. Biochemical characteristics of the patients.

\begin{tabular}{|c|c|c|c|}
\hline Biomarkers & $\begin{array}{c}\text { T0 } \\
\text { Mean } \pm \text { Standard } \\
\text { Deviation } \\
\text { (range) }\end{array}$ & $\begin{array}{c}\mathrm{T} 2 \\
\text { Mean } \pm \text { Standard } \\
\text { Deviation } \\
\text { (range) }\end{array}$ & $p$-Value \\
\hline $\begin{array}{l}\text { TBARS } \\
(\mu \mathrm{mol} / \mathrm{L})\end{array}$ & $\begin{array}{l}0.73 \pm 0.29 \\
(0.50-1.36)\end{array}$ & $\begin{array}{l}0.68 \pm 0.29 \\
(0.39-1.23)\end{array}$ & 0.551 \\
\hline $\begin{array}{c}\text { TAC } \\
(\mathrm{mmol} \mathrm{DPPH} / \mathrm{L})\end{array}$ & $\begin{array}{l}49.49 \pm 4.94 \\
(38.15-56.23)\end{array}$ & $\begin{array}{l}49.14 \pm 9.80 \\
(29.33-63.51)\end{array}$ & 0.691 \\
\hline $\begin{array}{c}\text { SOD } \\
(\mathrm{U} / \mathrm{mL})\end{array}$ & $\begin{array}{c}283.99 \pm 16.05 \\
(231.00-297.15)\end{array}$ & $\begin{array}{c}291.62 \pm 8.03 \\
(275.62-305.66)\end{array}$ & 0.074 \\
\hline $\begin{array}{l}\text { GPx } \\
(\mathrm{U} / \mathrm{L})\end{array}$ & $\begin{array}{l}1617.35 \pm 750.40 \\
(656.14-3768.58)\end{array}$ & $\begin{array}{c}1441.82 \pm 345.52 \\
(1093.56-2187.12)\end{array}$ & 0.333 \\
\hline $\begin{array}{c}\mathrm{CAT} \\
(\mathrm{U} / \mathrm{mgHb})\end{array}$ & $\begin{array}{l}1.07 \pm 0.63 \\
(0.41-2.38)\end{array}$ & $\begin{array}{l}1.41 \pm 0.77 \\
(0.62-3.54)\end{array}$ & 0.008 * \\
\hline $\begin{array}{c}\mathrm{GSH} \\
(\mathrm{mg} / \mathrm{dL})\end{array}$ & $\begin{array}{l}7.63 \pm 1.60 \\
(4.80-10.60)\end{array}$ & $\begin{array}{c}8.16 \pm 3.01 \\
(4.00-12.60)\end{array}$ & 0.490 \\
\hline
\end{tabular}

${ }^{*} p<0.05$, significantly different. TBARS, thiobarbituric acid reactive species; TAC, total antioxidant capacity; SOD, superoxide dismutase; GPx, glutathione peroxidase; CAT, catalase; GSH, reduced glutathione; DPPH, 2,2'-diphenyl-1-picrylhydrazyl radical reagent.

CAT values were significantly different between the two periods of time (before and after the TB treatment). CAT activity was lower at baseline than after treatment, as shown in Table 2.

As Table 2 displays, for the other biomarkers, we did not find significant differences between the values obtained before and after the TB treatment.

We found a moderate positive correlation between GSH and TAC ( $r=0.63, p$-value $=0.046)$ and GSH and SOD $(r=0.64, p$-value $=0.041)$ at T2, as shown in Table 3 and Figure 1. 
Table 3. Spearman coefficients with correlation matrix.

\begin{tabular}{ccccccccc}
\hline & Age & Weight & TBARS_T2 & $\begin{array}{c}\text { TAC } \\
- \text { T2 }\end{array}$ & $\begin{array}{c}\text { SOD } \\
- \text { T2 }\end{array}$ & $\begin{array}{c}\text { GPx } \\
- \text { T2 }\end{array}$ & $\begin{array}{r}\text { CAT } \\
\text { _T2 }\end{array}$ & GSH_T2 \\
\hline Age & 1.00 & & & & & & \\
\hline Weight & -0.10 & 1.00 & & & & & & \\
\hline TBARS_T2 & 0.29 & 0.26 & 1.00 & & & & & \\
\hline TAC_T2 & -0.45 & -0.10 & -0.28 & 1.00 & & & \\
\hline SOD_T2 & -0.40 & -0.22 & -0.40 & 0.29 & 1.00 & & \\
\hline GPx_T2 & -0.02 & -0.29 & -0.42 & -0.32 & 0.45 & 1.00 & & \\
\hline CAT_T2 & -0.45 & 0.39 & -0.23 & -0.05 & 0.24 & 0.02 & 1.00 & \\
\hline GSH_T2 & -0.47 & -0.20 & -0.05 & $0.63 *$ & $0.64 *$ & 0.05 & 0.32 & 1.00 \\
\hline
\end{tabular}

* $p<0.05$. TBARS, thiobarbituric acid reactive species; TAC, total antioxidant capacity; SOD, superoxide dismutase; $\mathrm{GPx}$, glutathione peroxidase; CAT, catalase; GSH, reduced glutathione.

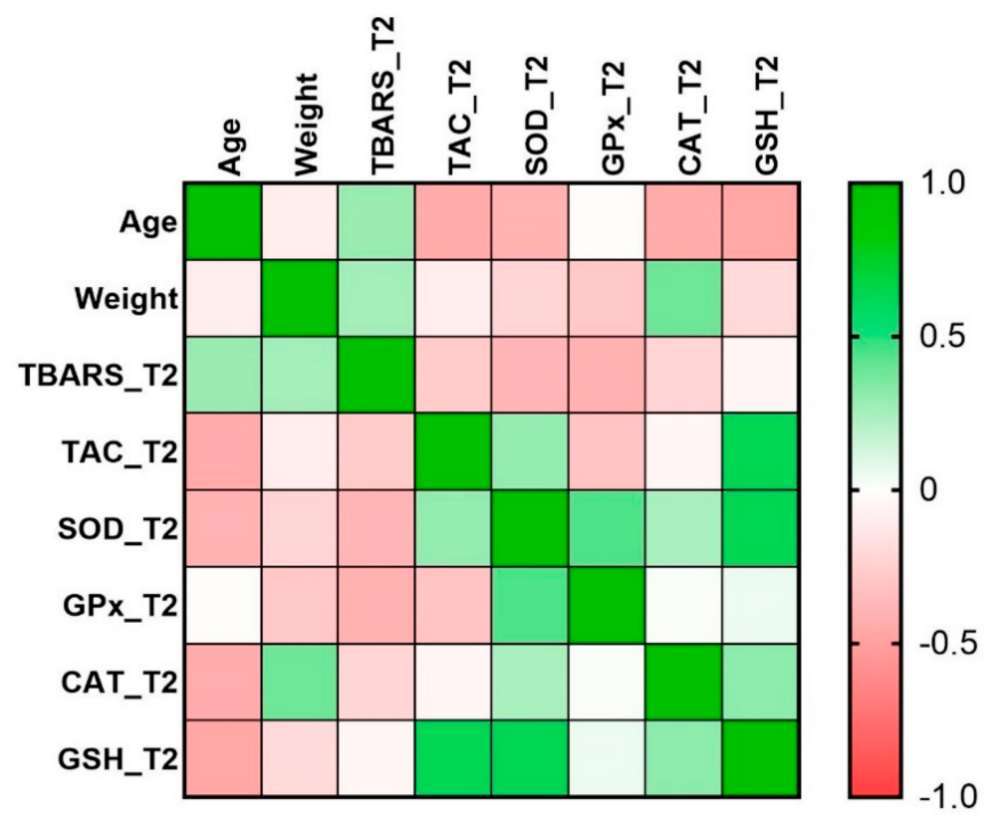

Figure 1. Heatmap of correlation matrix. TBARS, thiobarbituric acid reactive species; TAC, total antioxidant capacity; SOD, superoxide dismutase; GPx, glutathione peroxidase; CAT, catalase; GSH, reduced glutathione. T2, after 60 days of antituberculosis treatment.

\section{Discussion}

Our pilot study analysed oxidative stress biomarkers and antioxidants status in pulmonary active TB patients, before and after two months of anti-TB treatment. M.tb. generates ROS through mitochondrial respiratory burst and intensively affects both normal lung function and host immune responses $[5,6,23]$. An altered antioxidant profile further contributes to disease evolution owing to an incapacity to properly remove the oxidative burden $[5,6,23]$. Superoxide radicals and hydrogen peroxide are products of flavoenzymes; cyclo- and lipo-oxygenases; as well as NADPH-dependent oxidase, a specific enzyme of phagocytes [23]. Hydrogen peroxide represents an important intermediate in more reactive radicals' synthesis, such as the hydroxyl radical (obtained through Fenton reaction, catalysed by $\mathrm{Fe}^{2+}$ or $\mathrm{Cu}^{2+}$ ), as the only ROS that penetrates cellular membranes [23]. CAT and GPx are responsible for hydrogen peroxide removal, while SOD counteracts superoxide radicals by dismutation to hydrogen peroxide $[5,6,23]$. However, if these enzymes are insufficient, free radicals accumulate within pulmonary tissue and attack membrane lipids, leading to lipid peroxidation and MDA synthesis as one of its final products [23]. 
The results we obtained underline higher TBARS plasmatic values and lower antioxidant defence at T0, suggesting increased lipid peroxidation rates, dysfunction of redox homeostasis, cytotoxic consequences, and implication of increased ROS in TB pathogenesis $[12,13,23]$. Nevertheless, ROS are used in M.tb. recognition and initiation of immune response [14]. ROS formation is dependent on proinflammatory cytokine and chemokine activity, which leads to a vicious circle in TB, as the bacilli chemoattract different immune cells and maintain tissue remodelling [14]. Decreased lipid peroxidation at T2, assessed through TBARS, suggests a delay or even prevention of pulmonary fibrosis, also due to higher plasmatic values of CAT and SOD that act as ROS scavengers [12,13]. Rajopadhye et al. [12] obtained similar results with our pilot study, as they correlate TBARS increased values with TB severity and pulmonary fibrosis development [12]. Lower TBARS values also emphasize a lower lipid peroxidation rate, suggesting a decrease in oxidative stress [23] after two months of DOTS.

All patients included in the study suggested poor immunity as they were diagnosed with malnutrition, also confirmed by statistical analysis regarding demographic and clinical data (Tables 1 and 2). The incapacity of neutralising oxidative stress, due to lower weight and wasting, is one of the most important risk factors in developing active TB [7,10,31,32]. Malnutrition and deficiency in various immunomodulatory vitamins, especially vitamin $\mathrm{D}$ deficiency, lead to weak promotion of monocytes and T-cells maturation, increased proinflammatory cytokine activity, and postponed phagosome-lysosome fusion by interfering with gene transcription [31-33].

Enzymatic antioxidants are present in higher concentrations in erythrocytes, and were thus quantified using hemolysates. Cellular oxidative damage, loss of mitochondrial membrane integrity, and impaired cellular function can also be controlled through glutathione activity, which regulates the redox cycle and maintains antioxidant functionality of ascorbic acid and tocopherol [8,14-16]. After 60 days of first-line treatment, GSH values increased, with its possible involvement in modulating cytokine activity and host response [17].

Although there are no aliments known until now with a direct antimycobacterial effect, proper body mass index can ensure host defence mechanisms, by upregulating intracellular GSH biosynthesis, one of the most important antioxidants [17]. Imbalance between ROS and antioxidants, due to intense and chronic macrophage activation [14], implies inadequate removal of oxidative stress, thus affecting the membrane and DNA of pulmonary host cells through an increased rate of lipid peroxidation. Our results agree with the findings in previous studies $[10,33,34]$. Isoniazid, one of the most administered first-line antituberculotic drugs, stimulates oxidative stress biomarkers and increases hepatotoxicity and nephrotoxicity, concomitant with antioxidant status reduction (SOD, GSH, and TAC), as Hassan et al. and Sharma et al. underline using rat models [33,34]. Needless to mention that all of our patients received first-line antituberculotic treatment.

SOD is involved in transforming superoxide radicals in less reactive peroxide, which is further reduced by CAT to oxygen and water, thus providing tissular protection $[13,14]$. Furthermore, ROS are eliminated through GPx and glutathione reductase activity, based on conversion of cellular GSH to its oxidized form and regeneration [13,14]. In fact, GPx is abundant in parenchymal lung cells, suggesting its particular implications in patients diagnosed with pulmonary active TB [35]. GSH is used in hydrogen peroxide reduction catalysed by GPx [23]. The reaction involves oxidation of Se- to SeOH, which further adds one to two sulfidic radicals, regenerating to Se- [23]. A significant reduction of SOD and CAT has been noted at T0 for our patients in comparison with T2, similar to other studies $[10,12,33,34]$. On the other hand, even though GPx and TAC slightly decreased at $\mathrm{T} 2$, it might be due to the small number of individuals who gave consent in participating in our study and a short timeline of monitorisation.

One of the strengths of our study is represented by the analysis of oxidative stress biomarkers and antioxidants status at two points of time. An evaluation of lipid peroxidation could lead to a better understanding of TB pathogenesis and could represent a useful tool in identification of individuals exposed to higher risk of progression [23]. To the best of 
our knowledge, there are few available recent studies that reported these plasmatic changes by comparing their immunomodulatory roles $[10,12,33,34]$. Moreover, we identified few studies that reported changes in plasmatic investigations before and after anti-TB treatment in humans $[10,12]$. We found that only Vidhya et al. analysed oxidative biomarkers status in pulmonary TB patients before and after pharmacotherapy, in the last 5 years, and they suggested that antioxidant co-supplementation could be useful in reducing TB severity [10]. All the patients included were only diagnosed with pulmonary active TB, which represents another strength, as comorbidities could influence variation of oxidative stress biochemical parameters. We also quantified alternative biomarkers specific for oxidative stress, instead of MDA, because of their higher stability and specificity and lower rate of variation through analysis steps [36].

The limitations of our study include the small number of patients, as it has been difficult to find new patients only diagnosed with pulmonary TB. Even further, our study was conducted between 1 November 2019 until 1 April 2020, when the COVID-19 pandemic forced us to stop visiting the two hospitals and including more TB patients. It might have also been interesting to compare our results from TB patients' samples with a control group, not diagnosed with pulmonary $\mathrm{TB}$, to highlight even more the oxidative damage in case of mycobacterial infection. A follow-up study assessing oxidative stress and antioxidants status in TB patients, after six months of antimycobacterial treatment, would also be helpful in establishing TB management strategies.

\section{Conclusions}

The present pilot study underlines the involvement of increased oxidative species and reduction of antioxidant status in developing pulmonary active TB. A host attempt to decrease lung injury by restoring prooxidant/antioxidant balance has also been noted in active pulmonary TB patients, possible leading to increased immunomodulatory effects.

All in all, the pathological outcomes are decided by a tremendous fight between antioxidants and pro-oxidants. Possible nutritional supplementation, based on antioxidants, could represent a novel approach in controlling TB. Further studies regarding modulation of redox balance need to follow up on biochemical changes in order to properly manage this public threat.

Author Contributions: Conceptualization, A.-D.M. and C.-G.P.; methodology, A.-D.M., A.T.-S., E.C.S., A.M.A., and C.-G.P.; software, A.T.-S.; validation, F.M.N. and M.M.; formal analysis, A.T.-S.; investigation, A.-D.M.; resources, F.M.N., M.M., and I.M.B.; data curation, A.-D.M., F.M.N., and M.M.; writing - original draft preparation, A.-D.M. and A.T.-S.; writing-review and editing, A.D.M., A.T.-S., and C.-G.P.; supervision, C.-G.P. All authors have read and agreed to the published version of the manuscript.

Funding: This research received no external funding.

Institutional Review Board Statement: The study was conducted according to the guidelines of the Declaration of Helsinki, and approved by the Ethics Committee from The University of Medicine and Pharmacy of Craiova, Romania (Nr.5/17.01.2019).

Informed Consent Statement: Informed consent was obtained from all subjects involved in the study.

Data Availability Statement: The data presented in this study are available on request from the corresponding author. The data are not publicly available due to patients' confidentiality.

Acknowledgments: We are thankful for the technical support provided by chemist Loredana Colhon from the Department of Biochemistry, University of Medicine and Pharmacy of Craiova, Romania, and to all the patients who gave consent for participating in the present study.

Conflicts of Interest: The authors declare no conflict of interest. 


\section{References}

1. WHO Europe-Tuberculosis News. Available online: http://www.euro.who.int/en/health-topics/communicable-diseases / tuberculosis /news / news/2019/3/drug-resistant-strains-could-become-the-dominant-form-of-tb-in-europe-its-time-to-endtb (accessed on 15 October 2020).

2. Uberti, F.; Morsanuto, V.; Molinari, C. Vitamin D in Oxidative Stress and Diseases. Crit. Eval. Vitam. D Basic Overv. 2017, 47-73. [CrossRef]

3. Brighenti, S.; Bergman, P.; Martineau, A.R. Vitamin D and tuberculosis: Where next? J. Intern. Med. 2018, 284, 145-162. [CrossRef] [PubMed]

4. Balcells, M.E.; Yokobori, N.; Hong, B.-Y.; Corbett, J.; Cervantes, J.L. The lung microbiome, vitamin D, and the tuberculous granuloma: A balance triangle. Microb. Pathog. 2019, 131, 158-163. [CrossRef]

5. Shastri, M.D.; Shukla, S.D.; Chong, W.C.; Dua, K.; Peterson, G.M.; Patel, R.P.; Hansbro, P.M.; Eri, R.; O’Toole, R.F. Role of Oxidative Stress in the Pathology and Management of Human Tuberculosis. Oxidative Med. Cell. Longev. 2018, 2018, 1-10. [CrossRef]

6. De Almeida, A.J.P.O.; Rezende, M.S.D.A.; Dantas, S.H.; Silva, S.D.L.; De Oliveira, J.C.P.L.; Azevedo, F.D.L.A.A.D.; Alves, R.M.F.R.; De Menezes, G.M.S.; Dos Santos, P.F.; Gonçalves, T.A.F.; et al. Unveiling the Role of Inflammation and Oxidative Stress on Age-Related Cardiovascular Diseases. Oxidative Med. Cell. Longev. 2020, 2020, 1-20. [CrossRef] [PubMed]

7. Vemula, M.H.; Ganji, R.; Sivangala, R.; Jakkala, K.; Gaddam, S.; Penmetsa, S.; Banerjee, S. Mycobacterium tuberculosis Zinc Metalloprotease-1 Elicits Tuberculosis-Specific Humoral Immune Response Independent of Mycobacterial Load in Pulmonary and Extra-Pulmonary Tuberculosis Patients. Front. Microbiol. 2016, 7, 418. [CrossRef] [PubMed]

8. Mohanty, S.; Molin, M.D.; Ganguli, G.; Padhi, A.; Jena, P.; Selchow, P.; Sengupta, S.; Meuli, M.; Sander, P.; Sonawane, A.; et al. Mycobacterium tuberculosis EsxO (Rv2346c) promotes bacillary survival by inducing oxidative stress mediated genomic instability in macrophages. Tuberculosis 2016, 96, 44-57. [CrossRef] [PubMed]

9. $\mathrm{Xu}, \mathrm{X}$.; Shen, M. Associations between vitamin D receptor genetic variants and tuberculosis: A meta-analysis. Innate Immun. 2019, 25, 305-313. [CrossRef]

10. Vidhya, R.; Rathnakumar, K.; Balu, V.; Pugalendi, K.V. Oxidative stress, antioxidant status and lipid profile in pulmonary tuberculosis patients before and after anti-tubercular therapy. Indian J. Tuberc. 2018, 66, 375-381. [CrossRef]

11. Gough, M.E.; Graviss, E.A.; Chen, T.-A.; Obasi, E.M.; May, E.E. Compounding effect of vitamin D3 diet, supplementation, and alcohol exposure on macrophage response to mycobacterium infection. Tuberculosis 2019, 116, S42-S58. [CrossRef]

12. Rajopadhye, S.H. Oxidative Stress Markers in Tuberculosis and HIV/TB Co-Infection. J. Clin. Diagn. Res. 2017, 11, BC24-BC28. [CrossRef]

13. Abrahams, S.; Haylett, W.L.; Johnson, G.; Carr, J.A.; Bardien, S. Antioxidant effects of curcumin in models of neurodegeneration, aging, oxidative and nitrosative stress: A review. Neuroscience 2019, 406, 1-21. [CrossRef]

14. Kruk, J.; Aboul-Enein, H.Y.; Kładna, A.; Bowser, J.E. Oxidative stress in biological systems and its relation with pathophysiological functions: The effect of physical activity on cellular redox homeostasis. Free Radic. Res. 2019, 53, 497-521. [CrossRef]

15. Tan, B.L.; Norhaizan, M.E.; Liew, W.-P.-P.; Rahman, H.S. Antioxidant and Oxidative Stress: A Mutual Interplay in Age-Related Diseases. Front. Pharmacol. 2018, 9, 1162. [CrossRef]

16. Amaral, E.P.; Vinhaes, C.L.; Oliveira-De-Souza, D.; Nogueira, B.; Akrami, K.M.; Andrade, B.B. The Interplay Between Systemic Inflammation, Oxidative Stress, and Tissue Remodeling in Tuberculosis. Antioxidants Redox Signal. 2021, 34, 471-485. [CrossRef] [PubMed]

17. Teskey, G.; Abrahem, R.; Cao, R.; Gyurjian, K.; Islamoglu, H.; Lucero, M.; Martinez, A.; Paredes, E.; Salaiz, O.; Robinson, B.; et al. Glutathione as a Marker for Human Disease. In Advances in Applied Microbiology; Elsevier BV: London, UK, 2018; Volume 87, pp. 141-159.

18. Farazi, A.; Didgar, F.; Sarafraz, A. The effect of vitamin D on clinical outcomes in tuberculosis. Egypt. J. Chest Dis. Tuberc. 2017, 66, 419-423. [CrossRef]

19. Wahyunitisari, M.R.; Mertaniasih, N.M.; Amin, M.; Artama, W.T.; Koendhori, E.B. Vitamin D, cell death pathways, and tuberculosis. Int. J. Mycobacteriology 2017, 6, 349-355. [CrossRef] [PubMed]

20. Gois, P.H.F.; Ferreira, D.; Olenski, S.; Seguro, A.C. Vitamin D and Infectious Diseases: Simple Bystander or Contributing Factor? Nutrients 2017, 9, 651. [CrossRef] [PubMed]

21. Liu, J.; Yeo, H.C.; Doniger, S.J.; Ames, B.N. Assay of Aldehydes from Lipid Peroxidation: Gas Chromatography-Mass Spectrometry Compared to Thiobarbituric Acid. Anal. Biochem. 1997, 245, 161-166. [CrossRef] [PubMed]

22. Spanidis, Y.; Mpesios, A.; Stagos, D.; Goutzourelas, N.; Bar-Or, D.; Karapetsa, M.; Zakynthinos, E.; Spandidos, D.A.; Tsatsakis, A.; Leon, G.; et al. Assessment of the redox status in patients with metabolic syndrome and type 2 diabetes reveals great variations. Exp. Ther. Med. 2016, 11, 895-903. [CrossRef]

23. Suresh, D.R.; Annam, V. Lipid peroxidation and total antioxidant capacity in health and disease-Pathophysiology and markers: An overview. Int. J. Med. Sci. Public Health 2013, 2, 478-479. [CrossRef]

24. Keles, M.; Taysi, S.; Sen, N.; Aksoy, H.; Akçay, F. Effect of Corticosteroid Therapy on Serum and CSF Malondialdehyde and Antioxidant Proteins in Multiple Sclerosis. Can. J. Neurol. Sci./J. Can. des Sci. Neurol. 2001, 28, 141-143. [CrossRef]

25. Janaszewska, A.; Bartosz, G. Assay of total antioxidant capacity: Comparison of four methods as applied to human blood plasma. Scand. J. Clin. Lab. Investig. 2002, 62, 231-236. [CrossRef] [PubMed] 
26. Pădureanu, R.; Albu, C.V.; Mititelu, R.R.; Bacanoiu, M.V.; Docea, A.O.; Calina, D.; Pădureanu, V.; Olaru, G.; Sandu, R.E.; Malin, R.D.; et al. Oxidative Stress and Inflammation Interdependence in Multiple Sclerosis. J. Clin. Med. 2019, 8, 1815. [CrossRef] [PubMed]

27. Paglia, D.E.; Valentine, W.N. Studies on the quantitative and qualitative characterization of erythrocyte glutathione perox-idase. J. Lab. Clin. Med. 1967, 70, 158-169.

28. Aebi, H. Catalase in vitro. In Methods in Enzymology; Packer, L., Ed.; Academic Press: Orlando, FL, USA, $1984 ;$ pp. $121-126$.

29. Sicińska, P.; Kik, K.; Bukowska, B. Human Erythrocytes Exposed to Phthalates and Their Metabolites Alter Antioxidant Enzyme Activity and Hemoglobin Oxidation. Int. J. Mol. Sci. 2020, 21, 4480. [CrossRef]

30. Jarosiewicz, M.; Krokosz, A.; Marczak, A.; Bukowska, B. Changes in the activities of antioxidant enzymes and reduced glutathione level in human erythrocytes exposed to selected brominated flame retardants. Chemosphere 2019, 227, 93-99. [CrossRef]

31. Hassanein, E.G.; Mohamed, E.E.; Baess, A.I.; El-Sayed, E.T.; Yossef, A.M.; Mohammad, E.E.S. The role of supplementary vitamin $\mathrm{D}$ in treatment course of pulmonary tuberculosis. Egypt. J. Chest Dis. Tuberc. 2016, 65, 629-635. [CrossRef]

32. Sun, D.; Luo, F.; Xing, J.-C.; Zhang, F.; Xu, J.; Zhang, Z.-H. 1,25(OH)2 D3 inhibited Th17 cells differentiation via regulating the NF-kB activity and expression of IL-17. Cell Prolif. 2018, 51, e12461. [CrossRef] [PubMed]

33. Sharma, R.; Battu, P.; Singla, M.; Goyal, N.; Sharma, V.L. Expression profile of markers of oxidative stress, injury and apoptosis in anti-tuberculosis drugs induced nephrotoxicity. Nephrology 2019, 24, 689-695. [CrossRef]

34. Hassan, H.M.; Guo, H.; Yousef, B.A.; Guerram, M.; Hamdi, A.M.; Zhang, L.; Jiang, Z. Role of Inflammatory and Oxidative Stress, Cytochrome P450 2E1, and Bile Acid Disturbance in Rat Liver Injury Induced by Isoniazid and Lipopolysaccharide Cotreatment. Antimicrob. Agents Chemother. 2016, 60, 5285-5293. [CrossRef] [PubMed]

35. Mahmoodpoor, A.; Hamishehkar, H.; Shadvar, K.; Ostadi, Z.; Sanaie, S.; Saghaleini, S.H.; Nader, N.D. The Effect of Intravenous Selenium on Oxidative Stress in Critically Ill Patients with Acute Respiratory Distress Syndrome. Immunol. Investig. 2019, 48, 147-159. [CrossRef] [PubMed]

36. Khoubnasabjafari, M.; Soleymani, J.; Jouyban, A. Avoid using spectrophotometric determination of malondialdehyde as a biomarker of oxidative stress. Biomark. Med. 2018, 12, 551-554. [CrossRef] [PubMed] 